chronic septic infection of unknown origin the jaw can only be excluded as a causal factor after a careful $X$ ray examination has been made, and this should be done however healthy the appearance of the gums and teeth. It is remarkable how frequently cases of fibrositis, arthritis, and similar chronic conditions are met with in which, though the gums and teeth appear perfectly healthy, an $X$ ray examination discloses definite septic foci round the apices of the teeth.

At the recent pathological meeting of the Medical Society of London on Jan. 10th, Sir William Hale-White and myself referred to a case of malignant endocarditis where the source of the infection was directly traceable to a septic focus round the apex of the left lower central incisor tooth. In this case an $X$ ray examination by Mr. C. A. Clark revealed a small abscess, though to ocular examination the gums and teeth appeared perfectly healthy. I am strongly of opinion that oral sepsis is one of the most important causes of gastric and duodenal ulcer and that the septic absorption of pathogenic streptococci often takes place through the blood stream, the gums and teeth appearing externally healthy. There is considerable experimental evidence by Rosenow and others to confirm this view. Certainly, however healthy may be the appearance of the gums, an $X$ ray examination of the teeth should be made in every suspected case of peptic ulcer.

$$
\text { I am, Sir, yours faithfully, }
$$

W. H. WILLCOX.

Welbeck-street, Cavendish-square, W., Jan. 24th, 1921.

\section{MALARIA IN THE EAST AFRICAN CAMPAIGN.} To the Editor of THE LANCET.

SIR, -Little has been published respecting the medical aspects of the campaign in East Africa, and the papers of Majors J. P. Johnson and K. Gilchrist ${ }^{1}$ and of Majors Johnson and Gilchrist and E. Hay-Michel ${ }^{2}$ are a welcome contribution of the greatest interest and importance. After clinical and laboratory experience in various hospitals in G.E.A. during 1916-1919 I should like to endorse many of their findings. In 1000 blood smears, most of them thick drops, I had 40 per cent. positive, of which 71 per cent., B. tertian; 26 per cent., subtertian; 3 per cent., mixed B.T. and S.T.; under 1 per cent., quartan. They made no mention of quartan infections; at Morogero I saw two cases in natives and only one case in a white man, so that possibly none were invalided to South Africa. Their figures naturally show a higher proportion of mixed infections, as these were more refractory to treatment and were therefore more liable to be invalided to South Africa. Higher dosage of quinine became the rule in the last one and a half years of the campaign, though medical officers new to the country often began with small "tonic" doses. In some hospitals a dosage of $60 \mathrm{gr}$. per diem was not uncommon. In my own cases I obtained better results with three-hourly doses of $10 \mathrm{gr}$. given as early in an attack as possible to a maximum of 30-40 gr. When an attack had been missed we endeavoured to produce mild tinnitus before the next rigor was due. In fact, the presence of tinnitus aurium was taken as a rough test of the absorption of quinine into the system. ${ }^{3}$ In the subtertian type of infection with continued fever it is important that repeated small doses should be given throughout the night as well as the day to a maximum of $45 \mathrm{gr}$. in 24 hours. I often thought that the omission of quinine between 6 P.M. and 8 A.M. accounted for the fact that medical officers could not control these cases with oral quinine. Majors Johnson and Gilchrist rightly lay great stress on the presence of parasitological as well as of clinical relapses. Unfortunately, "bed-space" was the deciding factor in hospitals in G.F.A., and it was late in the campaign before convalescent camps (Dodoma and Nakuru) had the benefit of a laboratory. The paper is a striking demonstration of the fact that only by repeated blood examination can one judge of the effects of our treatment, a matter which has been too often disregarded in weighing the merits of different drugs and modes of administration. The relapse of 14 per cent. of previous "negatives" is not higher than one would expect. The promotion of the general powers of resist. ance of the body is duly appreciated by Majors Johnson and Gilehrist. During the years 1917-1918 how futile were our drugs against the effects of climate and the debility of our patients, and how striking the difference made by evacuation to Nairobi, Kijabe, and Nakuru (4000 feet).

As regards treatment with "606" I can testify to the beneficial effect in malarial cachexia and in the convalescent stage of blackwater fever. Captain D. S. Harvey, of the 15th Stationary Hospital, and later myself, used it (intramuscularly) in several cases, and Dr. R. W. Burkitt, of Nairobi, B.E.A., has elsewhere published his good results in civil cases. The action of arsenic as a stimulant to the hæmopoietic system is to cause a better type of red cell to be passed into currency, the spleen has thus less destructive work to do, gets rid of its débris and hence becomes smaller. I believe that the shrinking of the spleen is as much due to this as to any diminished activity of malarial parasites. I cannot help thinking. that the effects on the liver which they ascribe to arsenic are chiefly due to the catharsis and light diet. In our V.D. section it was not unusual for an attack of malaria to occur within 48 hours after injection of " 606 " " and in the few cases of malaria in which I tried " 606 " alone had eventually to be given quinine. I am, therefore, most sceptical about the parasiticidal action of arsenic in malaria. The great lesson of their paper is that chronic malaria in debilitated subjects can be overcome only by adequate quininisation, combined with general tonic measures and that constant blood examination is necessary to control the treatment.

I am, Sir, yours faithiully,

W. S. DAWSON, M.B., M.R.C.P.,

Hanwell, Jan. 16th, 1920 Late 15th Stationary Hospital, G.E.A.

\section{INSURANCE MEDICAL RECORDS.}

To the Editor of THE LANCE'.

SIR,-At this juncture the leading article in your issue of Jan. 8th serves a very useful purpose. Just such a reasoned and sane pronouncement is much needed, for the numerous meetings held to discuss the record cards have been marked by much unwisdom in speech and resolution. Had these proceedings taken place in camera it would have been deplorable enough, but, unfortunately, in most instances the presence of pressmen has been courted, and their reports, as presented in the various papers, partake either of the nature of political propaganda or light comedy, and do little to uphold the dignity or intelligence of the medical profession.

At the very outset of the insurance agitation years ago $\mathrm{Mr}$. Lloyd George was reported to have said: "Remember, National Insurance is not merely a doctor's endowment society," and we should do well to keep this pronouncement in mind. We may take what is called "panel practice" to be the germ, or foundation, of what it is hoped will one day grow into an efficient State Medical Service. Even now panel doctors are State servants holding a Government con tract with definite conditions, of which record keeping is one. As State servants we have no concern with political or other like considerations. Our duty is to loyally carry out the terms of the contract we have accepted. Undoubtedly the record cards present features open to discussion, but they are sound in principle, a step in the right direction, and a great advance on the previous card system. If we approach the health authorities in a reasonable spirit, in time improvements will doubtless be made, but there is little in the present agitation to encourage the Department to give us a patient hearing. Is it reasonable to claim that the medical any more than any other profession is entirely faultless? There are doctors who do, and doctors who do not, take their panel practice seriously and probably for all of us, and certainly for the latter it is a good thing that we should have, in the record cards, to give an account of our stewardship.

I am, Sir, yours faithfully

Havant, Jan. 22nd, 1921.

ARTHUR J. GEDGE. 